\title{
Supermedicus Award for Professor Cezary Kowalewski
}

Adv Dermatol Allergol 2017; XXXIV (2): 184

DOI: https://doi.org/10.5114/ada.2017.67088

On October 22, 2016, the nineteenth edition of the National Economic Plebiscite was held in Warsaw. The purpose of the plebiscite organized by the Warsaw Chamber of Entrepreneurs is the promotion of the people and entities engaged in medical activities that significantly affect the level of services offered, their availability, quality and patient safety.

This year, the winner of the prestigious Supermedicus award and the title of the Medical Personality of the Year was Professor Cezary Kowalewski - Head of the Department of Dermatology and Immunodermatology, Medical University of Warsaw (Figure 1).

Professor Cezary Kowalewski was honored for longstanding medical, scientific and charity activity for patients with epidermolysis bullosa (EB) and other rare skin disorders. Professor Kowalewski was the first in Poland to create the outpatient clinic, which included care of almost all Polish patients with EB. His research over the past several years, carried out using the grants of the State Committee for Scientific Research (KBN), Ministry of Science and Higher Education (MNiSzW) and National Science Center (NCN), resulted in the genetic and clinical characterization of Polish patients with EB in the form of an international EB database.
In 2015, Professor Kowalewski was the beneficiary of a multimillion grant of the National Centre of Research and Development (NCBiR) - Strategmed II aimed to create modern dressings using stem cells dedicated to treatment of wounds in the course of EB. For the last two years Professor Kowalewski has coordinated clinical trials on new topical drugs in a group of patients with the most severe strains of junctional and dystrophic EB.

In addition to his daily work on EB in the medical and scientific field, Professor Kowalewski takes an active part in conferences and charity meetings with patients with EB and their families, which are aimed to popularize knowledge and management of the disease. He has also contributed to the total reimbursement of dressings dedicated to Polish patients with EB. Moreover, Professor Kowalewski has also created a group of experts from various fields of medicine (genetics, gastroenterology, dentistry, dietetics, surgery, pediatrics), who provide regular multidisciplinary care to Polish patients with EB.

Sincerely yours, Katarzyna Woźniak

President of the Warsaw branch of the Polish Society of Dermatology

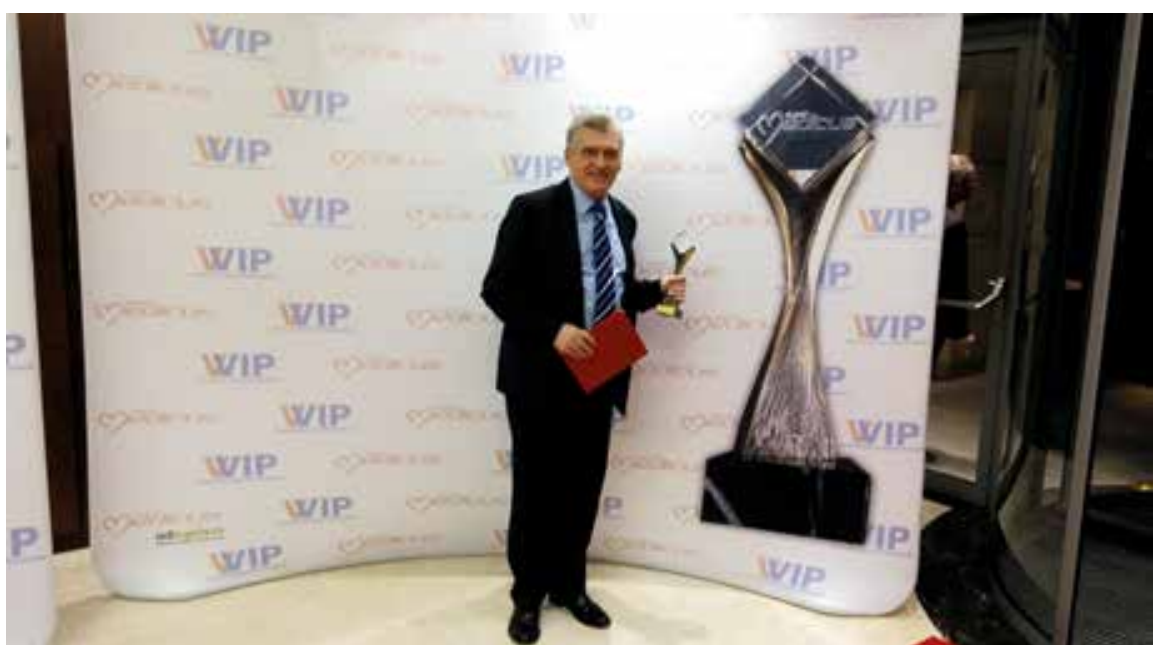

Figure 1. Professor Cezary Kowalewski honored with the Supermedicus award for longstanding activity for patients with epidermolysis bullosa 